PAPER • OPEN ACCESS

Structural, vibrational and electronic properties of $\mathrm{SnMBO}_{4}(\mathrm{M}=\mathrm{Al}, \mathrm{Ga})$ : a predictive hybrid DFT study

To cite this article: Mariano Curti et al 2019 J. Phys.: Condens. Matter 31345701

View the article online for updates and enhancements.

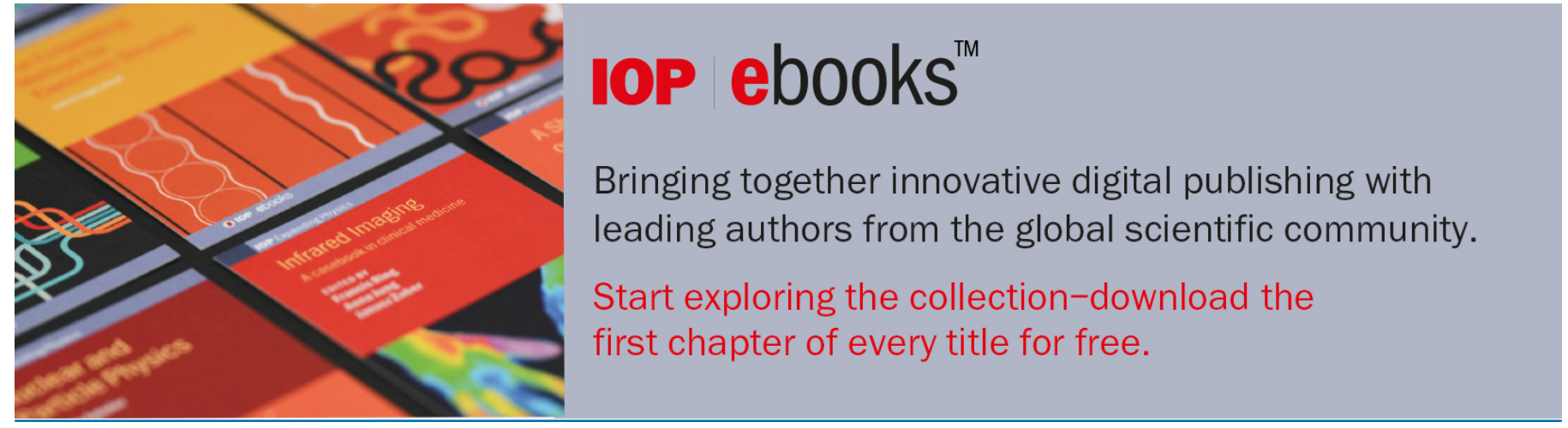

This content was downloaded from IP address 194.95 .157 .29 on 04/11/2020 at 07:47 


\title{
Structural, vibrational and electronic properties of $\mathrm{SnMBO}_{4}(\mathrm{M}=\mathrm{Al}, \mathrm{Ga})$ : a predictive hybrid DFT study
}

\author{
Mariano Curti ${ }^{1,2,3}{ }^{D}$, Cecilia B Mendive ${ }^{1,2,7} \oplus$, Thomas Bredow ${ }^{4}$, \\ M Mangir Murshed ${ }^{5,6}$ (b) and Thorsten M Gesing ${ }^{5,6}$ (1)
}

\footnotetext{
${ }^{1}$ Departamento de Química, Facultad de Ciencias Exactas y Naturales, Universidad Nacional de Mar del Plata, Dean Funes 3350, 7600 Mar del Plata, Argentina

2 IFIMAR, CONICET/Facultad de Ciencias Exactas y Naturales, Universidad Nacional de Mar del Plata, Dean Funes 3350, 7600 Mar del Plata, Argentina

${ }^{3}$ Institut für Technische Chemie, Gottfried Wilhelm Leibniz Universität Hannover, Callinstrasse 3, 30167

Hanover, Germany

${ }^{4}$ Mulliken Center for Theoretical Chemistry, Institut für Physikalische und Theoretische Chemie,

Universität Bonn, Beringstr. 4, D-53115 Bonn, Germany

${ }^{5}$ University of Bremen, Institute of Inorganic Chemistry and Crystallography, Leobener Strasse 7, D-28359 Bremen, Germany

${ }^{6}$ University of Bremen, MAPEX Center for Materials and Processes, Bibliothekstrasse 1, D-28359

Bremen, Germany

E-mail: cbmendive@mdp.edu.ar
}

Received 3 April 2019, revised 26 April 2019

Accepted for publication 9 May 2019

Published 4 June 2019

\begin{abstract}
We propose two new members of the mullite-type family, $\mathrm{SnAlBO}_{4}$ and $\mathrm{SnGaBO}_{4}$, and carry out an in-depth study of their crystal properties using the hybrid method PW1PW. Both are isostructural to $\mathrm{PbMBO}_{4}(\mathrm{M}=\mathrm{Fe}, \mathrm{Mn}, \mathrm{Al}, \mathrm{Ga})$, which show axial negative linear compressibility (ANLC), among other interesting features. We find that, although $\mathrm{Sn}^{2+}$ is susceptible of being oxidized by oxygen, a suitable range of experimental parameters exists in which the compounds could be synthesized. We observe absence of ANLC below $20 \mathrm{GPa}$ and explain it by the small space occupied by the lone electron pairs, as indicated by the small length of the corresponding Liebau Density Vectors. In agreement with this fact, the structures present a low number of negative mode-Grüneisen parameters, which may also suggest lack of negative thermal expansion. The electronic properties show a remarkable anisotropic behaviour, with a strong dependence of the absorption spectra on light polarization direction.
\end{abstract}

Keywords: lone electron pair, stereochemical activity, anisotropy, elastic properties, mullite-type

S] Supplementary material for this article is available online

(Some figures may appear in colour only in the online journal)

\section{Introduction}

Since the report on $\mathrm{PbMBO}_{4}$ (with $\mathrm{M}=\mathrm{Al}, \mathrm{Ga}, \mathrm{Fe}, \mathrm{Mn}, \mathrm{Cr}$; space group: Pnma) by Park et al [1-3] this family of compounds has drawn considerable interest due to their broad

\footnotetext{
${ }^{7}$ Author to whom any correspondence should be addressed. $1361-648 X / 19 / 345701+10 \$ 33.00$
}

range of properties. Of interest are the axial negative thermal expansion (ANTE) in the $\boldsymbol{a}$-direction [4], the axial negative linear compressibility (ANLC) of the $b$ lattice parameter [5], the dynamic stereochemically active lone electron pairs (LEPs) of $\mathrm{Pb}^{2+}$ cations [6], and the 1D Heisenberg magnetic chains for $\mathrm{M}=\mathrm{Fe}, \mathrm{Cr}$, or $\mathrm{Mn}$ [7]. The structural stability of $\mathrm{PbMBO}_{4}$ mainly requires a stereochemically active cation (i.e. $\mathrm{Pb}^{2+}$ ), a 
rigid $\mathrm{BO}_{3}$ trigonal planar unit, and a suitably sized M-cation forming edge-sharing octahedra that run parallel to the $c$-axis [2]. Since the radius of the $\mathrm{Sn}^{2+}$ cation is similar to that of $\mathrm{Pb}^{2+}$ [8], these two cations are expected to be readily exchanged in the structure, showing $5 s^{2}$ and $6 s^{2}$ LEP activities, respectively. Whereas $\mathrm{Pb}^{2+}$ is stable [9], compounds with $\mathrm{Sn}^{2+}$ are usually moderate reducing agents [10]. Therefore, syntheses of $\mathrm{SnMBO}_{4}$ compounds may not be as easy as those of $\mathrm{PbMBO}_{4}$ using conventional solid state methods at open conditions.

This work presents an $a b$ initio study of the structural properties of $\mathrm{SnMBO}_{4}$, with $\mathrm{M}=\mathrm{Al}$ and $\mathrm{Ga}$ (nonstandard Pnam mullite setting). We primarily employ the hybrid method PW1PW [11], and base our choice on two criteria. On the one hand, the PW1PW functional has been shown to outperform several other functionals, including the hybrid B3LYP, in the description of structural and energetic parameters of solids [11]. Therefore, the first reason is that of exactitude, which extends to the description of a vast array of crystalline compounds [12-14]. On the other hand, although the title compounds have not yet been synthesized, several members of the mullite-type family (including isostructural $\mathrm{PbAlBO}_{4}$ ) have been studied with the PW1PW functional [4, 15-17], showing good agreement with experimental data. Consequently, to perform a meaningful comparison between our study and the available information we employ here the same functional. On this basis, we calculate the Gibbs free energies for the decomposition of $\mathrm{SnMBO}_{4}$ as a function of temperature and oxygen pressure, which are important for determining conditions where the compounds may be stable. By means of pressure-constrained optimizations we also study their elastic properties, motivated by previous reports of ANTE [4] and ANLC [5] in isostructural compounds. In order to improve the atomic understanding of such properties, we also investigate the phonon dispersion and density of states, together with their pressure-dependent behaviour, which allows the calculation of isothermal mode Grüneisen parameters. Additionally, we calculate the electronic density of states and refractive indices, which are expected to benefit from the use of a hybrid method [11, 18]. Nevertheless, since the density functional theory (DFT) is a ground-state one, we also employ the $G W$-BSE (Bethe-Salpeter equations) method for the calculation of the optical excitation spectra under different light polarizations [19], which may be of interest for potential non-linear optic applications. Finally, we calculate the Wang-Liebau eccentricity parameters [20] and Liebau Density vectors [17], to rationalize the effect of the LEP stereochemical activity on the elastic behaviour of the compounds.

This study will guide the experimental work by providing initial values for structural features. Additionally, the atomic interpretation of the elastic and thermal properties of these compounds will also help to understand the crystal physicochemical properties of other members of the family.

\section{Computational procedures}

All structure optimizations, electronic structure and frequency calculations were performed with the crystalline orbital program CRYSTAL14 [21], employing the hybrid method
PW1PW [11], in which 20\% HF exchange is mixed with the PWGGA exchange functional [22]. The studied structures were optimized using the experimental crystallographic data of $\mathrm{PbAlBO}_{4}$ [15] and $\mathrm{PbGaBO}_{4}$ [1] as the starting geometries of $\mathrm{SnAlBO}_{4}$ and $\mathrm{SnGaBO}_{4}$, respectively. All basis sets were taken from the CRYSTAL website database. The MonkhorstPack shrinking factor was set to 8, corresponding to 125 independent $k$-points in the irreducible part of the Brillouin zone. A very large integration grid with 75 radial points and 974 angular points was adopted for the numerical integration of the exchange-correlation energy. The truncation of Coulomb and exchange integrals was set to 9, 9, 9, 14 and 42 in logarithmic values. The Anderson method [23] was used for convergence acceleration. Harmonic frequencies at the $\Gamma$-point of the Brillouin zone were calculated by numerically computing the second derivatives of the energy with respect to the atomic positions, and diagonalizing the mass-weighted Hessian matrix in Cartesian coordinates, as implemented in CRYSTAL14 [24, 25]. A Gaussian smearing function with a $15 \mathrm{~cm}^{-1}$ width was applied to the resulting modes for plotting the IR and Raman spectra and phonon density of states. This was chosen as a representative value from the observed full widths at half maximum (FWHM) in the experimental $\mathrm{PbAlBO}_{4}$ Raman spectrum [15], which range from $12 \mathrm{~cm}^{-1}$ to $22 \mathrm{~cm}^{-1}$. The refractive indices were calculated by means of the 'Coupled Perturbed Hartree-Fock/Kohn-Sham' method [26-28]. Reference calculations of $\mathrm{PbAlBO}_{4}$ and $\mathrm{TiO}_{2}$ were carried out with the same methodology. The crystal orbital overlap population analysis [29] was performed with CRYSTAL17 [30].

Optical spectra were calculated for the optimized structure of $\mathrm{SnAlBO}_{4}$ obtained with CRYSTAL-PW1PW employing the $G W$-BSE method as implemented in the GPAW program [31]. The quasiparticle energies were calculated with the $G_{0} W_{0}$ approach applying an approximate vertex correction $\left(G_{0} W_{0} \Gamma\right)$ based on the renormalized adiabatic LDA (rALDA) kernel [32]. The $G W$ energy cut-off $E_{\operatorname{cut} G W}$ was set to $150 \mathrm{eV}$. The initial wavefunction was obtained with the LDA functional [33] and a plane-wave basis set delimited by an energy cut-off of $600 \mathrm{eV}$. The Bethe-Salpeter equations [19] were solved for eight occupied and eight virtual bands using an energy cut-off of $200 \mathrm{eV}$. The dielectric function was calculated in the range $0.0-6.0 \mathrm{eV}$.

\section{Results and discussion}

The similarity in size and chemical behaviour between tin and lead apparently points towards the feasibility of the synthesis of $\mathrm{SnMBO}_{4}$ compounds. Our calculations show that both $\mathrm{SnAlBO}_{4}$ and $\mathrm{SnGaBO}_{4}$ are stable with respect to their decomposition into the corresponding oxides:

$$
\mathrm{SnMBO}_{4}(\mathrm{~s}) \rightarrow \frac{1}{2} \mathrm{M}_{2} \mathrm{O}_{3}(\mathrm{~s})+\mathrm{SnO}(\mathrm{s})+\frac{1}{2} \mathrm{~B}_{2} \mathrm{O}_{3}(\mathrm{~s}) .
$$

The change in the standard Gibbs free energy $\left(\Delta G_{298 \mathrm{~K}}^{0}\right)$ at $298 \mathrm{~K}$ corresponding to the formation of the oxides from $\mathrm{SnAlBO}_{4}$ and $\mathrm{SnGaBO}_{4}$ are $87.0 \mathrm{~kJ} \mathrm{~mol}^{-1}$ and $83.3 \mathrm{~kJ} \mathrm{~mol}^{-1}$, 
respectively. For comparison, we have obtained a value of $61.2 \mathrm{~kJ} \mathrm{~mol}^{-1}$ for $\mathrm{PbAlBO}_{4}$ (a readily synthesized compound [3]) using the same methodology.

$\mathrm{Sn}^{\mathrm{II}}$ compounds are susceptible of being oxidized into $\mathrm{Sn}^{\mathrm{IV}}$ due to their reducing properties [10], and are unstable towards their oxidation by air. In contrast, the inert pair effect stabilizes the $2+$ oxidation state for lead. It is thus important to ascertain whether the $\mathrm{SnMBO}_{4}$ compounds are stable towards their oxidation:

$$
\mathrm{SnMBO}_{4}(\mathrm{~s})+\frac{1}{2} \mathrm{O}_{2}(\mathrm{~g}) \rightarrow \frac{1}{2} \mathrm{M}_{2} \mathrm{O}_{3}(\mathrm{~s})+\mathrm{SnO}_{2}(\mathrm{~s})+\frac{1}{2} \mathrm{~B}_{2} \mathrm{O}_{3}(\mathrm{~s}) .
$$

We find that $\Delta G_{298 \mathrm{~K}}^{0}$ for reaction (2) is $-174 \mathrm{~kJ} \mathrm{~mol}^{-1}$ and $-178 \mathrm{~kJ} \mathrm{~mol}^{-1}$ for $\mathrm{SnAlBO}_{4}$ and $\mathrm{SnGaBO}_{4}$, respectively. Therefore, their decomposition is highly favoured under an oxygen partial pressure of $100 \mathrm{kPa}$ and a temperature of $298 \mathrm{~K}$. The value of $\Delta G$, however, is affected by those variables: a lower oxygen partial pressure, and a higher temperature, stabilizes $\mathrm{SnMBO}_{4}$. The change in the Gibbs free energy for reaction (2) as a function of the oxygen partial pressure at three different temperatures is shown in figure 1. Irrespective of the significantly different sizes, the M-cation has a minor effect on the calculated values. Of particular notes, both temperature and oxygen pressure play important roles in the stability of $\mathrm{SnMBO}_{4}$. For instance, at a temperature of $1173 \mathrm{~K}$, the compounds are stable under oxygen pressures lower than $\sim 5 \cdot 10^{-2}$ $\mathrm{Pa}$. Since both conditions are experimentally attainable [34] we predict that the compounds could be readily synthesized. Whether the compounds remain metastable under ambient conditions is outside the scope of this work, but the finding of favourable conditions hints to this possibility [35].

For the comparatively lower temperatures of $973 \mathrm{~K}$ and $773 \mathrm{~K}$ the maximum tolerable oxygen partial pressures get significantly lowered, to $\sim 6 \cdot 10^{-6} \mathrm{~Pa}$ and $\sim 6 \cdot 10^{-12} \mathrm{~Pa}$, respectively. This is explained by the negative entropy change $\Delta S_{298 \mathrm{~K}}^{0}$ of the reactions (around $-111 \mathrm{~J} \mathrm{~K}^{-1} \mathrm{~mol}^{-1}$ for both Al- and Ga-cations), which leads to a higher exergonicity for reaction (2) at decreasing temperatures, and thus favours the decomposition of $\mathrm{SnMBO}_{4}$.

Once the conditions at which the compounds could be synthesized have been determined, the crystalline properties of $\mathrm{SnAlBO}_{4}$ and $\mathrm{SnGaBO}_{4}$ are predicted. The lattice parameters, atomic positions, anisotropic displacement parameters and selected interatomic distances are given in tables 1, 2, S1 and S2 (supplementary information (available online at stacks.iop. org/JPhysCM/31/345701/mmedia)), respectively. The lattice parameters of $\mathrm{SnAlBO}_{4}$ are smaller than those of $\mathrm{SnGaBO}_{4}$ due to the smaller size of the $\mathrm{Al}^{3+}$ cation with respect to $\mathrm{Ga}^{3+}$ [36]. The experimental values of $\mathrm{PbAlBO}_{4}$ [3] ( $a=692.09$ (5) pm, $b=802.15(6) \mathrm{pm}, c=571.34(4) \mathrm{pm})$ and $\mathrm{PbGaBO}_{4}$ [1] $(a=699.44(10) \mathrm{pm}, b=824.95(11) \mathrm{pm}, c=589.25(8) \mathrm{pm})$ show similar trends. That is, the $a$-cell parameter is $\sim 3 \%$ larger for $\mathrm{SnMBO}_{4}$ than that of the $\mathrm{PbMBO}_{4}$ structure; $b$-cell parameter is $\sim 5 \%$ larger for $\mathrm{PbMBO}_{4}$; and $c$-remains similar. The changes of the cell parameters lead to similar cell volumes for $\mathrm{SnAlBO}_{4}$ and $\mathrm{PbAlBO}_{4}\left(313.9 \cdot 10^{6} \mathrm{pm}^{3}\right.$ and $317.2 \cdot 10^{6} \mathrm{pm}^{3}$, respectively), and $\mathrm{SnGaBO}_{4}$ and $\mathrm{PbGaBO}_{4}\left(333.0 \cdot 10^{6} \mathrm{pm}^{3}\right.$
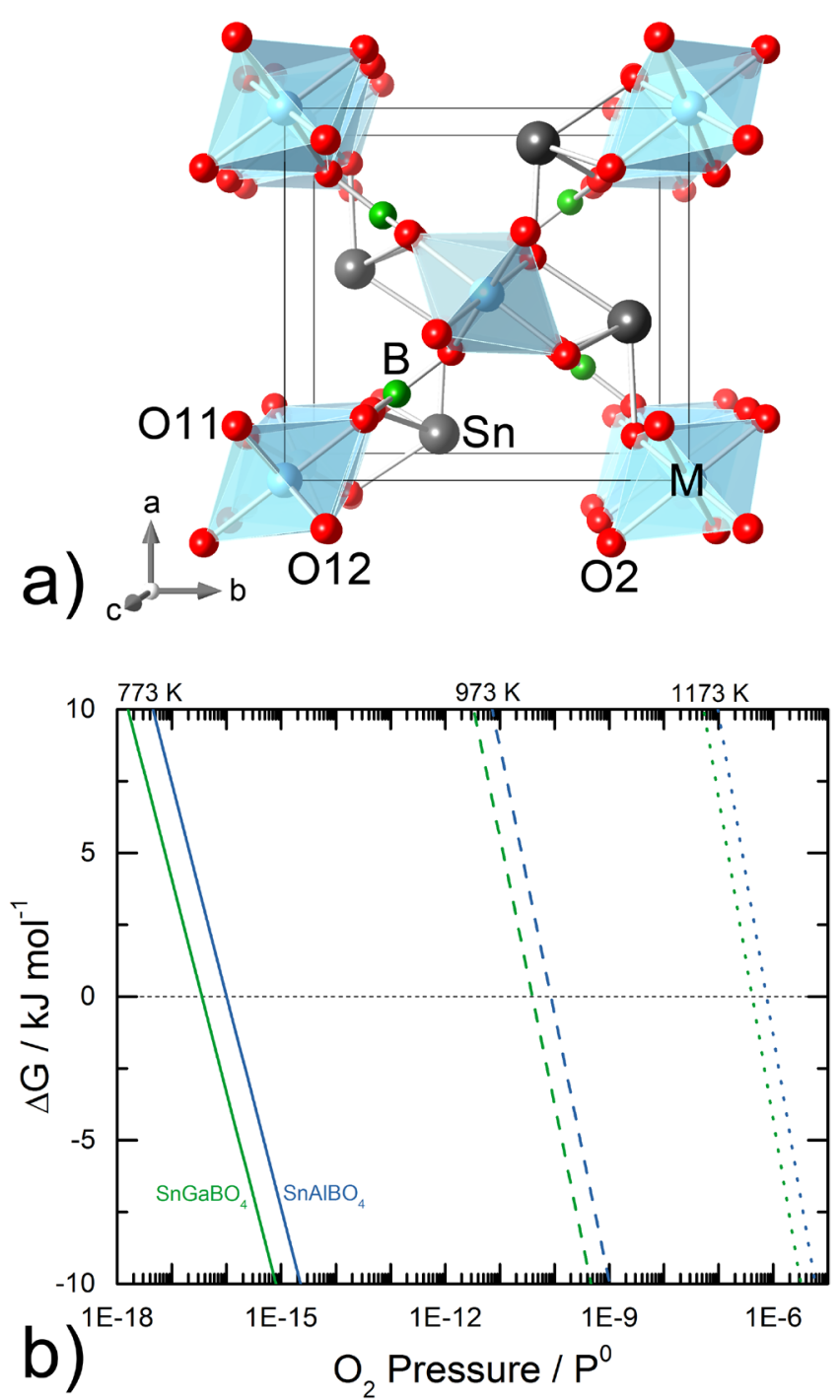

Figure 1. (a) Crystal structure of $\mathrm{SnMBO}_{4}(\mathrm{M}=\mathrm{Al}, \mathrm{Ga})$. (b) Change in the Gibbs free energy for the decomposition of $\mathrm{SnMBO}_{4}$ by oxygen uptake into $\mathrm{SnO}_{2}+1 / 2 \mathrm{M}_{2} \mathrm{O}_{3}+1 / 2 \mathrm{~B}_{2} \mathrm{O}_{3}$, as a function of the oxygen partial pressure at three different temperatures. $P^{0}$ denotes the standard pressure, $100 \mathrm{kPa}$.

Table 1. Crystal data of $\mathrm{SnAlBO}_{4}$ and $\mathrm{SnGaBO}_{4}$.

\begin{tabular}{|c|c|c|}
\hline Empirical formula & $\mathrm{SnAlBO}_{4}$ & $\mathrm{SnGaBO}_{4}$ \\
\hline $\begin{array}{l}\text { Formula } \\
\text { weight } / 10^{-3} \mathrm{~kg} \\
\mathrm{~mol}^{-1}\end{array}$ & 220.50 & 263.24 \\
\hline Space group & Pnam (62) & Pnam (62) \\
\hline$a / \mathrm{pm}$ & 711.2 & 720.4 \\
\hline$b / \mathrm{pm}$ & 772.2 & 784.9 \\
\hline$c / \mathrm{pm}$ & 571.7 & 588.9 \\
\hline $\begin{array}{l}\text { Cell } \\
\text { volume } / 10^{-30} \mathrm{~m}^{3}\end{array}$ & 314.0 & 333.0 \\
\hline$Z$ & 4 & 4 \\
\hline Density/g cm ${ }^{-3}$ & 4.694 & 5.262 \\
\hline $\begin{array}{l}\text { Refractive indices } \\
\text { in principal axes }\end{array}$ & $1.894,2.029,1.943$ & $1.904,2.017,1.945$ \\
\hline $\begin{array}{l}\text { Electronic } \\
\text { bandgap/eV }\end{array}$ & 3.88 & 4.44 \\
\hline
\end{tabular}


Table 2. Atomic coordinates of $\mathrm{SnAlBO}_{4}$ and $\mathrm{SnGaBO}_{4}$.

\begin{tabular}{|c|c|c|c|c|c|c|c|c|}
\hline \multirow[b]{2}{*}{ Atom } & \multirow[b]{2}{*}{ Wyckoff } & \multirow[b]{2}{*}{ Site symmetry } & \multicolumn{3}{|c|}{$\mathrm{SnAlBO}_{4}$} & \multicolumn{3}{|c|}{$\mathrm{SnGaBO}_{4}$} \\
\hline & & & $x$ & $y$ & $z$ & $x$ & $y$ & $z$ \\
\hline Sn1 & $4 \mathrm{c}$ &.$m$ & 0.0769 & 0.3675 & $1 / 4$ & 0.0797 & 0.3660 & $1 / 4$ \\
\hline M1 & $4 a$ & -1 & 0 & 0 & 0 & 0 & 0 & 0 \\
\hline B1 & $4 c$ &.$m$ & 0.7789 & 0.7320 & $1 / 4$ & 0.7843 & 0.7255 & $1 / 4$ \\
\hline O11 & $4 c$ &.$m$ & 0.8387 & 0.0917 & $3 / 4$ & 0.8290 & 0.0854 & $3 / 4$ \\
\hline $\mathrm{O} 12$ & $4 c$ &.$m$ & 0.1028 & 0.8816 & $3 / 4$ & 0.1028 & 0.8749 & $3 / 4$ \\
\hline $\mathrm{O} 2$ & $8 \mathrm{~d}$ & 1 & 0.1630 & 0.1945 & 0.9579 & 0.1613 & 0.2024 & 0.9532 \\
\hline
\end{tabular}
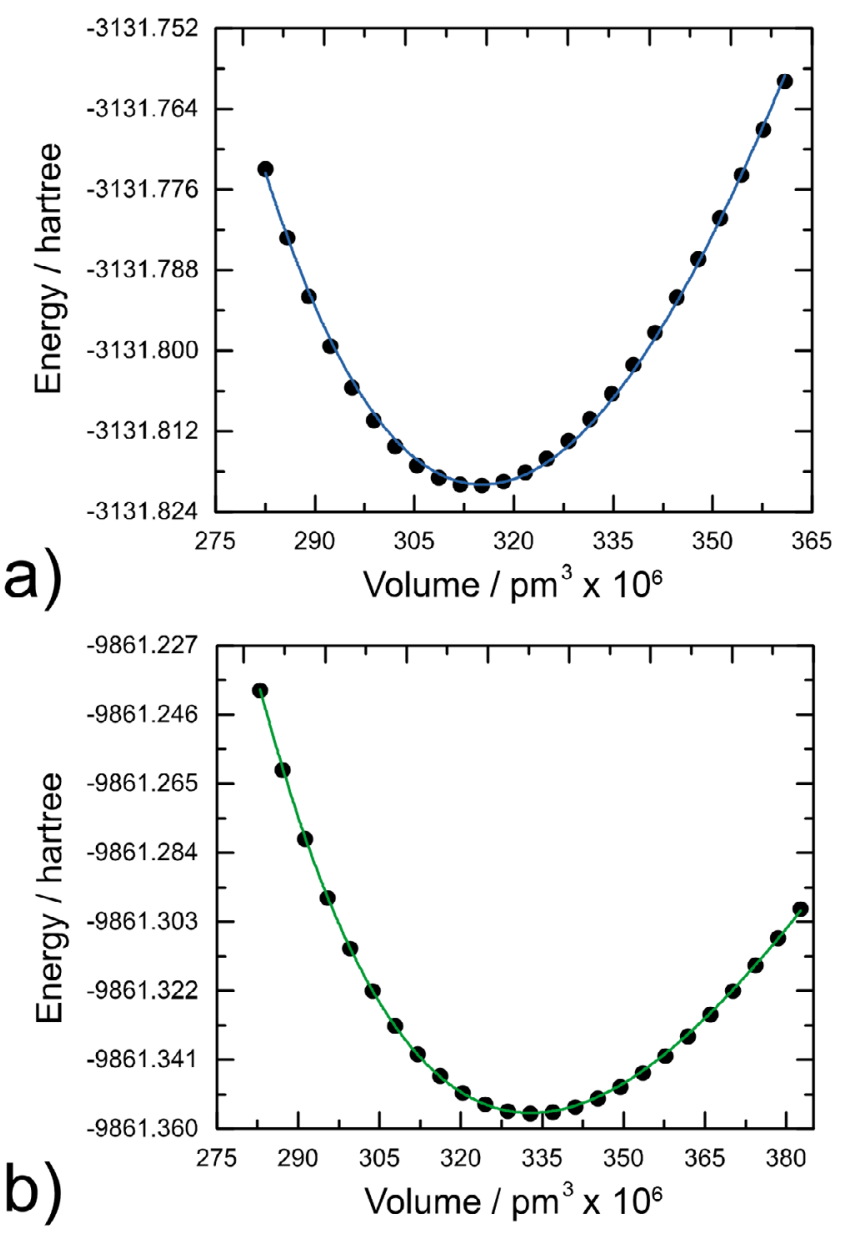

Figure 2. Calculated energy versus volume curves for (a) $\mathrm{SnAlBO}_{4}$ and (b) $\mathrm{SnGaBO}_{4}$. Circles show the calculated data points while lines are fittings to the 3rd order Birch-Murnaghan equation of state.

and $340.0 \cdot 10^{6} \mathrm{pm}^{3}$, respectively). The slightly larger values can be explained in terms of the larger size of $\mathrm{Pb}^{2+}$ cations with respect to $\mathrm{Sn}^{2+}$. The variation in the $a$ - and $b$-cell parameters between $\mathrm{SnMBO}_{4}$ and $\mathrm{PbMBO}_{4}$ can be explained in terms of the stereochemical activity and orientation of the respective LEPs, leading to a mechanical analogy of a Nürnberg scissor. That is, the expansion in the $\boldsymbol{b}$-direction occurs at the expense of the contraction in the $\boldsymbol{a}$-direction. Members of the mullitetype family usually show a correlation between $a$ and $b$, while the $c$ lattice parameter behaves independently [37].
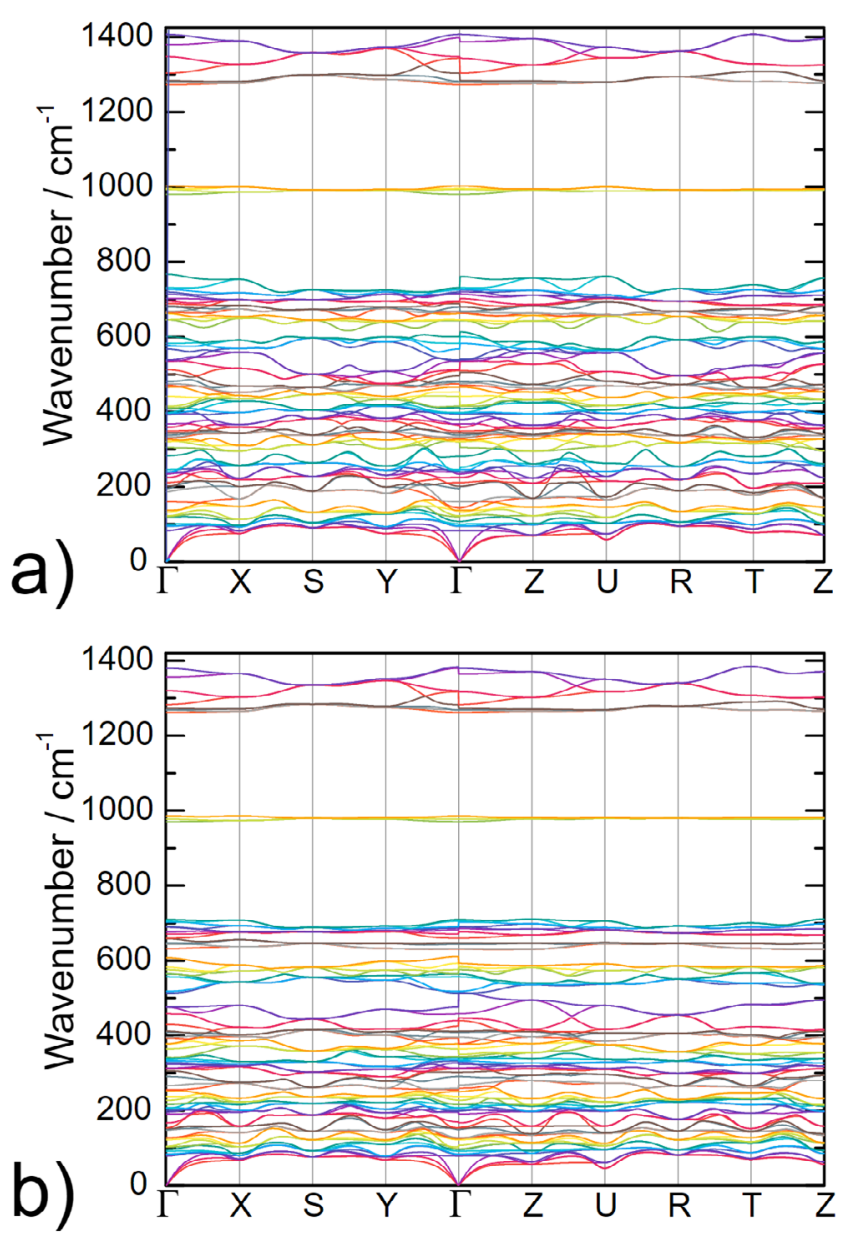

Figure 3. Phonon dispersion diagrams along the selected highsymmetry directions for (a) $\mathrm{SnAlBO}_{4}$ and (b) $\mathrm{SnGaBO}_{4}$.

The bulk moduli $K_{0}$ and their first pressure-derivatives $K_{0}^{\prime}$ were calculated by fitting the energy versus volume curves, as shown in figure 2, using the 3rd order Birch-Murnaghan equation of state. The obtained values are $K_{0}=100.3 \mathrm{GPa}$ and $K_{0}^{\prime}=3.88$ for $\mathrm{SnAlBO}_{4}$ and $K_{0}=91.9$ and $K_{0}^{\prime}=6.34$ for $\mathrm{SnGaBO}_{4}$. As could be expected from its larger unit cell volume, the bulk modulus is lower for $\mathrm{SnGaBO}_{4}$, following a simple rule occasionally valid for isostructural compounds $[38,39]$. The bulk moduli are relatively larger than that of $\mathrm{PbAlBO}_{4}$ of 76.1(6) (PW1PW: 77.4(2) GPa), a fact attributable to a lower influence of the $\mathrm{Sn}^{2+}$ LEP in the $\mathrm{SnMBO}_{4}$ properties, as will be discussed later. 

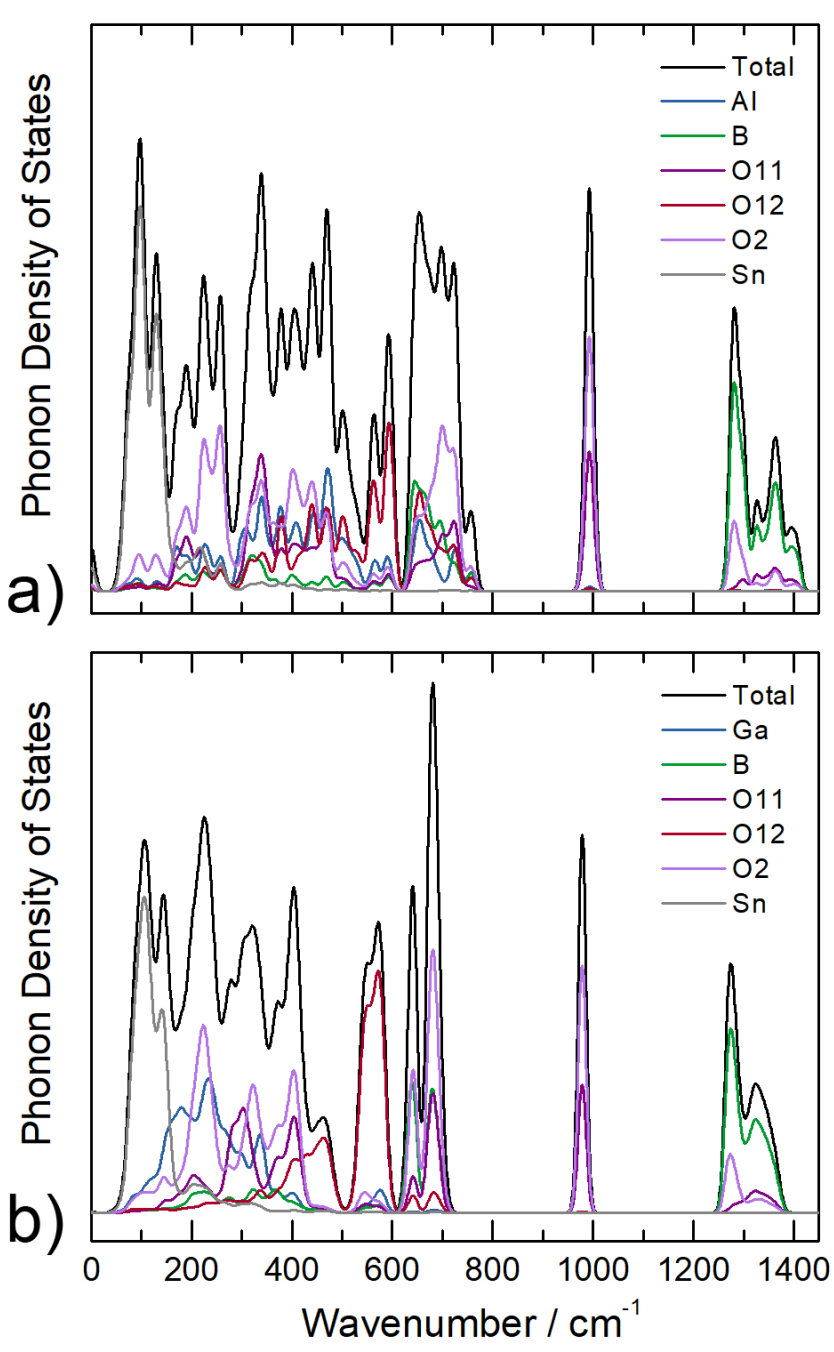

Figure 4. Phonon density states and the contributions from the constituent atoms for (a) $\mathrm{SnAlBO}_{4}$ and (b) $\mathrm{SnGaBO}_{4}$.

The optimized cell volumes at different pressures can be used as an alternative procedure for bulk moduli calculations by fitting to the 3rd order Birch-Murnaghan state equation. By these means we obtained $K_{0}=107.3 \mathrm{GPa}$ and $K_{0}^{\prime}=4.6$ for $\mathrm{SnAlBO}_{4}$, and $K_{0}=97.9 \mathrm{GPa}$ and $K_{0}^{\prime}=5.0$ for $\mathrm{SnGaBO}_{4}$, in agreement with the energy versus volume procedure (figure 2).

An interesting property shown by structurally related compounds is the ANLC, i.e. an increase in one of the lattice parameters when the crystal is subjected to hydrostatic pressure [40]. For instance, isostructural $\mathrm{PbFeBO}_{4}$ shows a $1.5 \%$ increase in its $b$-cell parameter under a pressure of $8 \mathrm{GPa}$ [5]. The proposed mechanism involves the concerted tilting of $\mathrm{BO}_{3}$ units [5], facilitated by the softness of the structure along the $\boldsymbol{a}$-direction (where the stereochemical active $\mathrm{Pb}^{2+}$ LEPs are predominantly located). Similar conclusions were drawn for $\mathrm{BiB}_{3} \mathrm{O}_{6}[40,41]$, in which the $\mathrm{Bi}^{3+}$ cations show stereochemical activity. We have therefore studied the behaviour of $\mathrm{SnMBO}_{4}$ structures under pressure. The evolution of the lattice parameters for both compounds is shown in figure $\mathrm{S} 1$. Of particular notes, unlike positive expansion in the $\boldsymbol{b}$-direction in some $\mathrm{PbMBO}_{4}$ compounds [5], all lattice

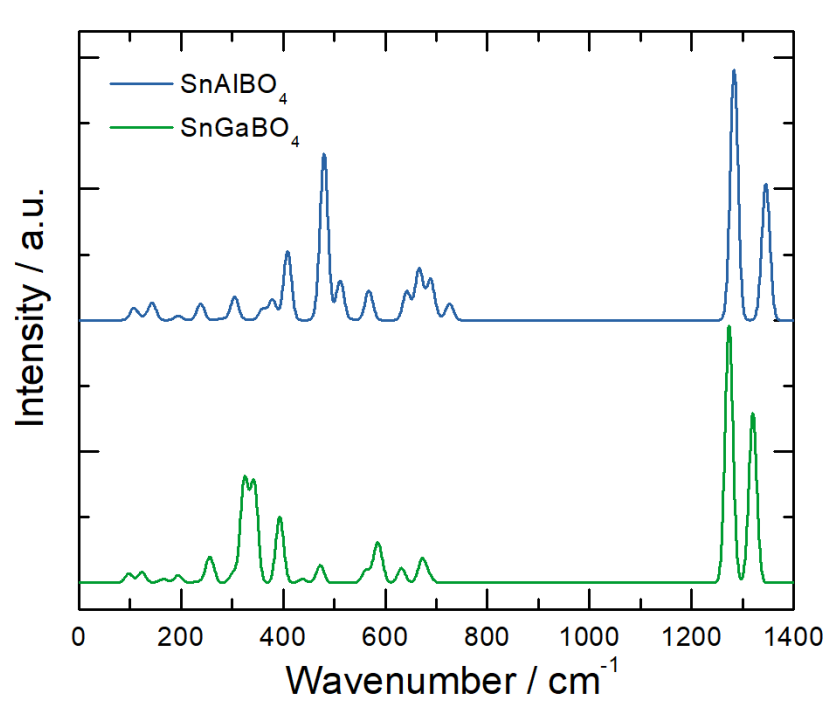

Figure 5. Calculated infrared spectra for $\mathrm{SnAlBO}_{4}$ and $\mathrm{SnGaBO}_{4}$.

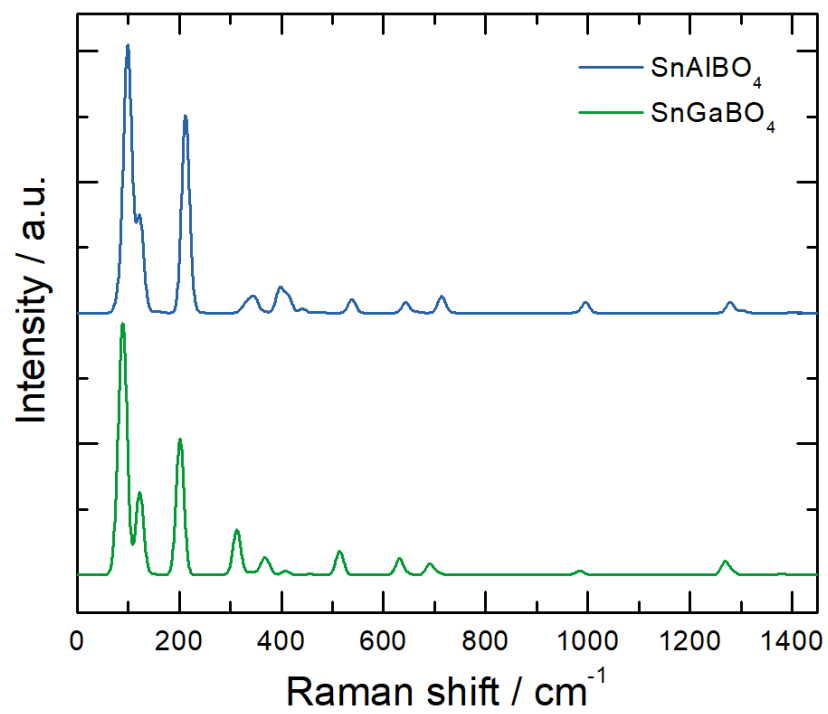

Figure 6. Calculated Raman spectra for $\mathrm{SnAlBO}_{4}$ and $\mathrm{SnGaBO}_{4}$. Intensities were calculated for a laser wavelength of $633 \mathrm{~nm}$ and a temperature of $298 \mathrm{~K}$.

parameters contract when pressure is increased up to $20 \mathrm{GPa}$. The proposed mechanism for the negative linear expansion of $\mathrm{PbFeBO}_{4}$ and $\mathrm{BiB}_{3} \mathrm{O}_{6}$ directly involves the stereochemically active LEPs. Therefore, the LEP of $\mathrm{Sn}^{2+}$ cations do not seem to influence the structure as strongly. As such, the incorporation of $\mathrm{Sn}^{2+}$ into the $\mathrm{PbFeBO}_{4}$ structure could be used to fine tune the ANLC property.

The phonon dispersion diagram for $\mathrm{SnMBO}_{4}$ is shown in figure 3. A band maximum composed of three Einstein-type frequencies (almost dispersionless) is observed in an isolated region near $1000 \mathrm{~cm}^{-1}$. The eigenvector analysis shows that this feature exclusively involves $\mathrm{O} 11$ and $\mathrm{O} 2$ vibrations. These oxygen atoms are also involved together with the B-atoms in the higher frequency $\left(1200-1400 \mathrm{~cm}^{-1}\right)$ region of the spectra. Two phononic band gaps are also observed for both compounds (figure 3). For $\mathrm{SnAlBO}_{4}$ they are in the ranges 765 

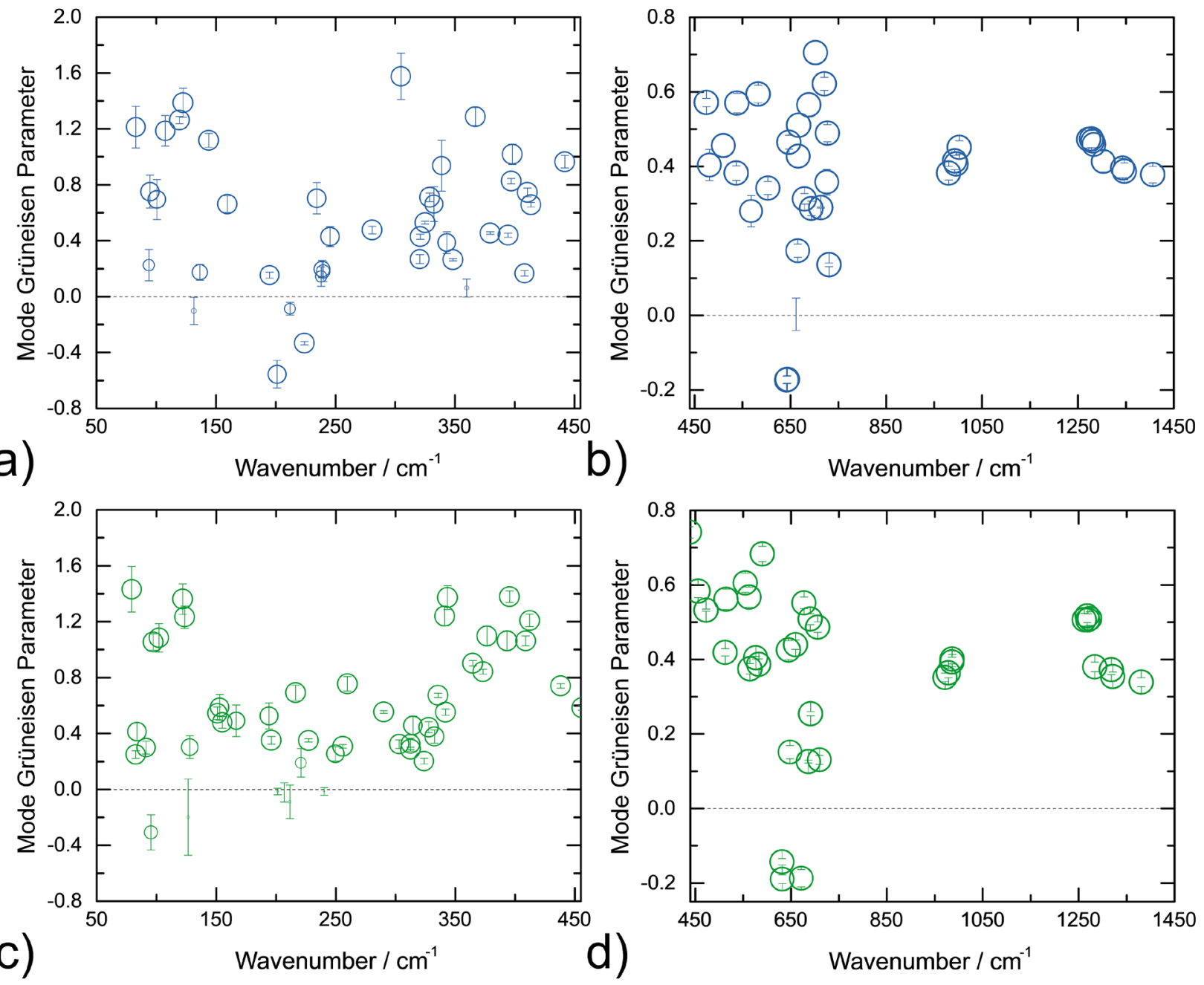

Figure 7. Mode Grüneisen parameters for the vibrational modes of (a) and (b) $\mathrm{SnAlBO}_{4}$ and (c) and (d) $\mathrm{SnGaBO}_{4}$. Circle sizes are proportional to the correlation coefficients, and the error bars refer to the uncertainty from the fitting.

to $980 \mathrm{~cm}^{-1}$ and 1000 to $1270 \mathrm{~cm}^{-1}$, while for $\mathrm{SnGaBO}_{4}$ they locate in 710 to $970 \mathrm{~cm}^{-1}$ and 985 to $1260 \mathrm{~cm}^{-1}$. Therefore, they show similar widths. Additionally, the lack of imaginary (negative) phonon frequencies further suggests that both compounds are stable.

The calculated phonon density of states (PDOSs) of $\mathrm{SnAlBO}_{4}$ and $\mathrm{SnGaBO}_{4}$ are shown in figure 4. The results for both compounds are very similar and are consistent with the dispersion diagrams (figure 3): a continuum of phonon states is observed in the $100-800 \mathrm{~cm}^{-1}$ range, an isolated band appears near $1000 \mathrm{~cm}^{-1}$, and another continuum locates at $1200-1400 \mathrm{~cm}^{-1}$. The projected PDOS of each constituent atom in the asymmetric unit cell shows that $\mathrm{Sn}^{2+}$ is involved in the $100-200 \mathrm{~cm}^{-1}$ range, $M$ in the $200-800 \mathrm{~cm}^{-1}$ range, and $B$ in the $600-800$ and the $1200-1400 \mathrm{~cm}^{-1}$ ranges. The vibrational features of $\mathrm{O} 11, \mathrm{O} 12$, and $\mathrm{O} 2$ are spread almost in the whole spectra with an exclusive contribution to the band maxima near $1000 \mathrm{~cm}^{-1}$.

The calculated infrared spectra of $\mathrm{SnMBO}_{4}$ are shown in figure 5. We applied a Gaussian line profile function for a better comparison with the experimental results (if available). Both spectra share similar features, with a multitude of bands in the 100 to $700 \mathrm{~cm}^{-1}$ range and two intense bands in the $1200-1400 \mathrm{~cm}^{-1}$ range. The latter are the superposition of three vibrational modes, as detailed in tables S2 and S3. The general features of the spectra are in principle agreement with both the experimental and the calculated IR spectra of $\mathrm{PbAlBO}_{4}$ [15]. By analogy with this compound, the 100 $200 \mathrm{~cm}^{-1}$ range can be attributed to $\mathrm{Sn}-\mathrm{O}$ related modes, the $200-600 \mathrm{~cm}^{-1}$ to $\mathrm{M}-\mathrm{O}$, and the $600-1400 \mathrm{~cm}^{-1}$ range to $\mathrm{B}-\mathrm{O}$.

The calculated Raman spectra for both compounds are shown in figure 6, where the intensities were corrected considering a laser wavelength of $633 \mathrm{~nm}$ and a temperature of $298 \mathrm{~K}$. The calculated spectra show again a qualitative agreement with the experimental spectrum of $\mathrm{PbAlBO}_{4}$ [15]. For future reference we list all calculated optical phonon modes in tables $\mathrm{S} 2$ and $\mathrm{S} 3$ in the supporting information.

Isostructural compounds $\left(\mathrm{PbAlBO}_{4}[15], \mathrm{PbFeBO}_{4}[4]\right)$ are known to show ANTE. It has been proposed that this behaviour could be related to a substantial number of negative mode Grüneisen parameters $\gamma_{i}$ [42]. The isothermal Grüneisen parameter is defined as: $\gamma_{i}=-\mathrm{d} \ln \omega_{i} / \mathrm{d} \ln V$, where $\omega_{i}$ is the frequency of the vibrational mode and $V$ the unit cell volume. The mode Grüneisen parameters $\gamma_{i}$ (at $0 \mathrm{~K}$ ) of the studied 

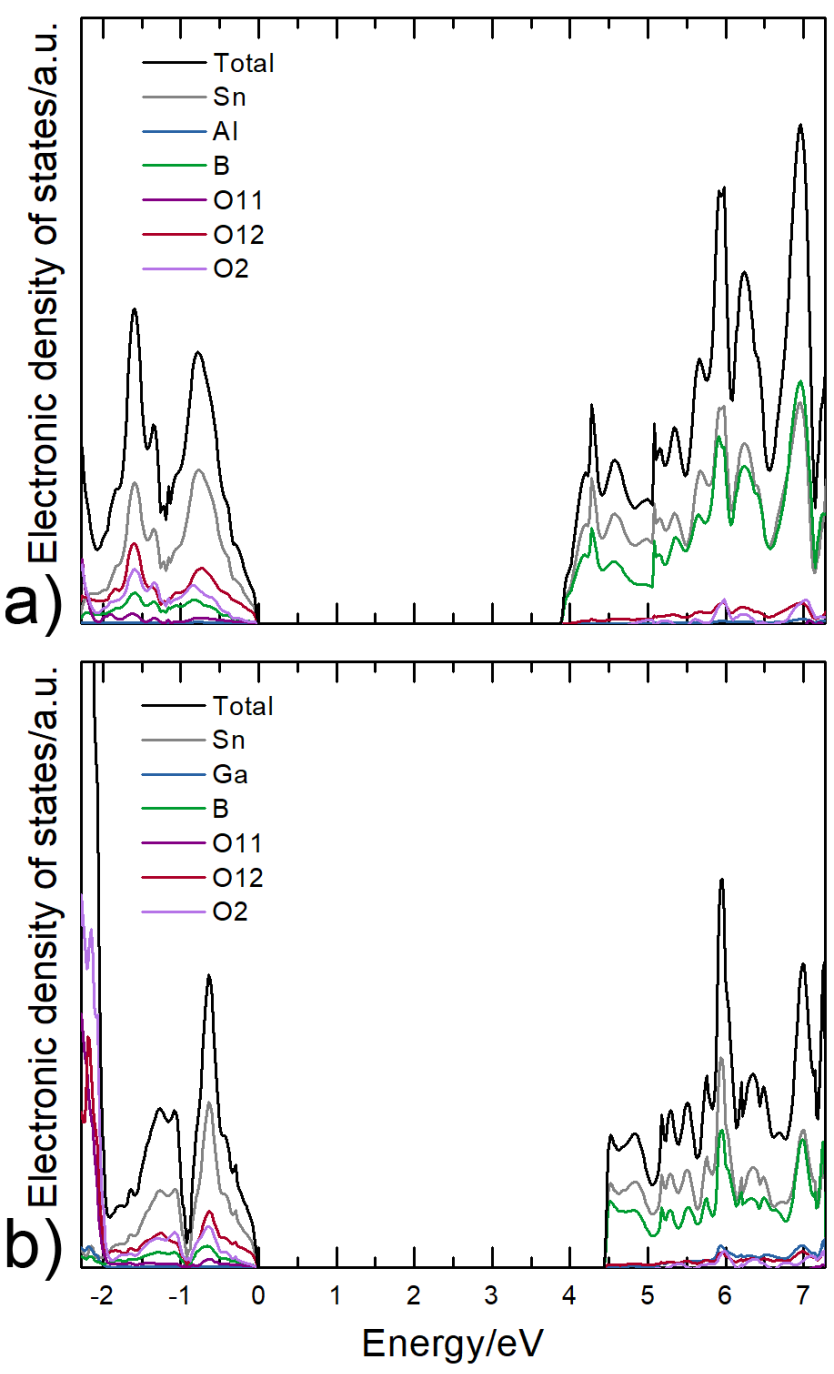

Figure 8. Density of electronic states for (a) $\mathrm{SnAlBO}_{4}$ and (b) $\mathrm{SnGaBO}_{4}$.

compounds are shown in figure 7. The frequencies of most modes change linearly with pressure, as illustrated by the sizes of the error bars. For modes with wavenumbers within the $50-450 \mathrm{~cm}^{-1}$ range they spread from -0.6 to 1.5 . Modes in the range $450-1450 \mathrm{~cm}^{-1}$ vary from -0.2 to 0.8 . Out of the 81 optical phonon modes, six and nine for $\mathrm{SnAlBO}_{4}$ and $\mathrm{SnGaBO}_{4}$, respectively, show negative $\gamma_{i}$. In comparison with $\mathrm{PbFeBO}_{4}$, which shows eight modes with negative $\gamma_{i}$ just considering the 36 Raman active ones [4], the fraction of negative $\gamma_{i}$ for $\mathrm{SnMBO}_{4}$ is considerably smaller. This could indicate a lack of anomalous properties such as ANTE. However, if even such small fraction of modes outweigh the positive ones, the ANTE phenomenon cannot be ruled out for $\mathrm{SnMBO}_{4}$.

The electronic density of states for $\mathrm{SnAlBO}_{4}$ and $\mathrm{SnGaBO}_{4}$ are shown in figure 8 . Both compounds show similar properties: the lower valence band is dominated by the O-states, the upper valence band has contributions from $\mathrm{O}^{2-}$ and $\mathrm{Sn}^{2+}$, and the conduction band shows contributions from both $\mathrm{Sn}$ and B. These general features are in agreement with the electronic structure of $\mathrm{PbAlBO}_{4}$.

The calculations of the refractive indices show that both $\mathrm{SnAlBO}_{4}$ and $\mathrm{SnGaBO}_{4}$ are biaxial materials, as expected

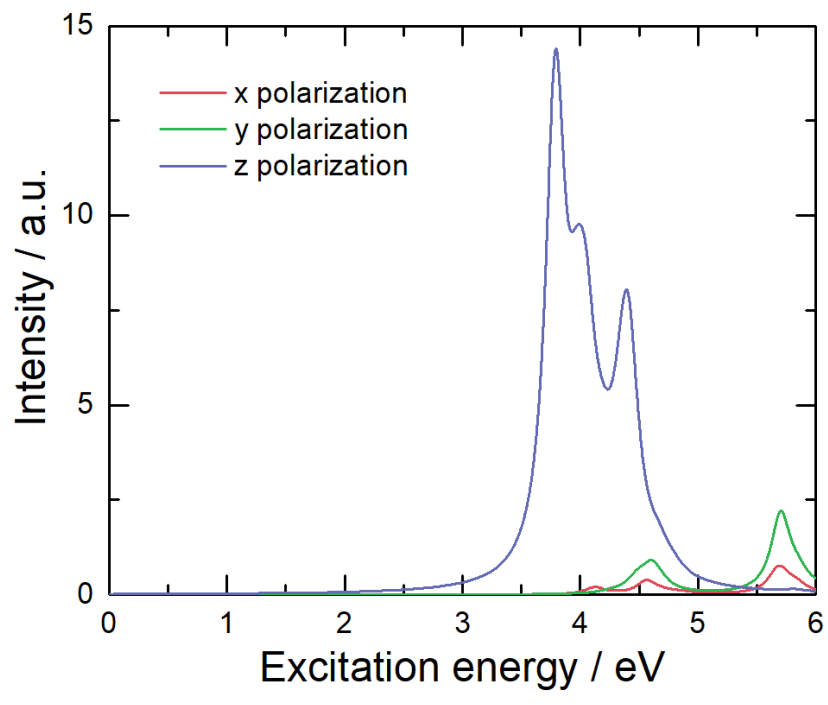

Figure 9. Calculated optical absorption spectrum of $\mathrm{SnAlBO}_{4}$ obtained with $G_{0} W_{0} \Gamma$-BSE.

from their orthorhombic crystal structure. The refractive indices along the principal axes are relatively large, ranging from 1.89 to 2.03 (table 1). These values are comparable to those calculated for $\mathrm{PbAlBO}_{4}(1.86,1.97$, and 1.92). A comparison of calculated values for the main polymorphs of $\mathrm{TiO}_{2}$ with experimental values indicate that the theoretical methodology employed here leads to an underestimation of $\sim 10 \%$, and thus the experimental refractive indices for $\mathrm{SnAlBO}_{4}$ and $\mathrm{SnGaBO}_{4}$ are expected to differ from the calculated values. The calculated electronic bandgaps are $3.88 \mathrm{eV}$ and $4.44 \mathrm{eV}$ for $\mathrm{SnAlBO}_{4}$ and $\mathrm{SnGaBO}_{4}$, respectively (table 1). Bandgap calculations using the present methodology overestimate the experimental optical bandgaps of $\mathrm{TiO}_{2}$ polymorphs by $\sim 0.6 \mathrm{eV}$, and therefore it could be also expected that the optical bandgaps for $\mathrm{SnMBO}_{4}$ are lower than the above-mentioned values.

To validate the electronic bandgaps calculated with DFT, since there are yet no experimental results to which they may be compared, we have calculated the optical absorption spectrum of $\mathrm{SnAlBO}_{4}$ using many-body perturbation theory as an internal theoretical reference. This was performed using the $G W$-BSE method as implemented in GPAW [31]. The $G W$ method (in the present case the non-self-consistent $G_{0} W_{0}$ approximation with vertex corrections $\left(G_{0} W_{0} \Gamma\right)$ was applied) takes into account polarization effects of the electron density near electrons and holes in the ground state. The resulting quasiparticle energies correspond to ionization energies and electron affinities. The Bethe-Salpeter equations [19] account for electron-hole interactions in excited states. They are solved based on the dielectric function and quasiparticle energies obtained with $G_{0} W_{0} \Gamma$. The first absorption maximum (figure 9) is near $3.8 \mathrm{eV}$, which is in accordance with the PW1PW electronic band gap $(3.88 \mathrm{eV})$. However, the onset of this peak, corresponding to the optical band gap, is located at much lower energies, slightly above $3.0 \mathrm{eV}$, like the calculation for rutile $\mathrm{TiO}_{2}$. Of particular notes, a strong anisotropy of the spectrum is observed (figure 9). The intensity along 

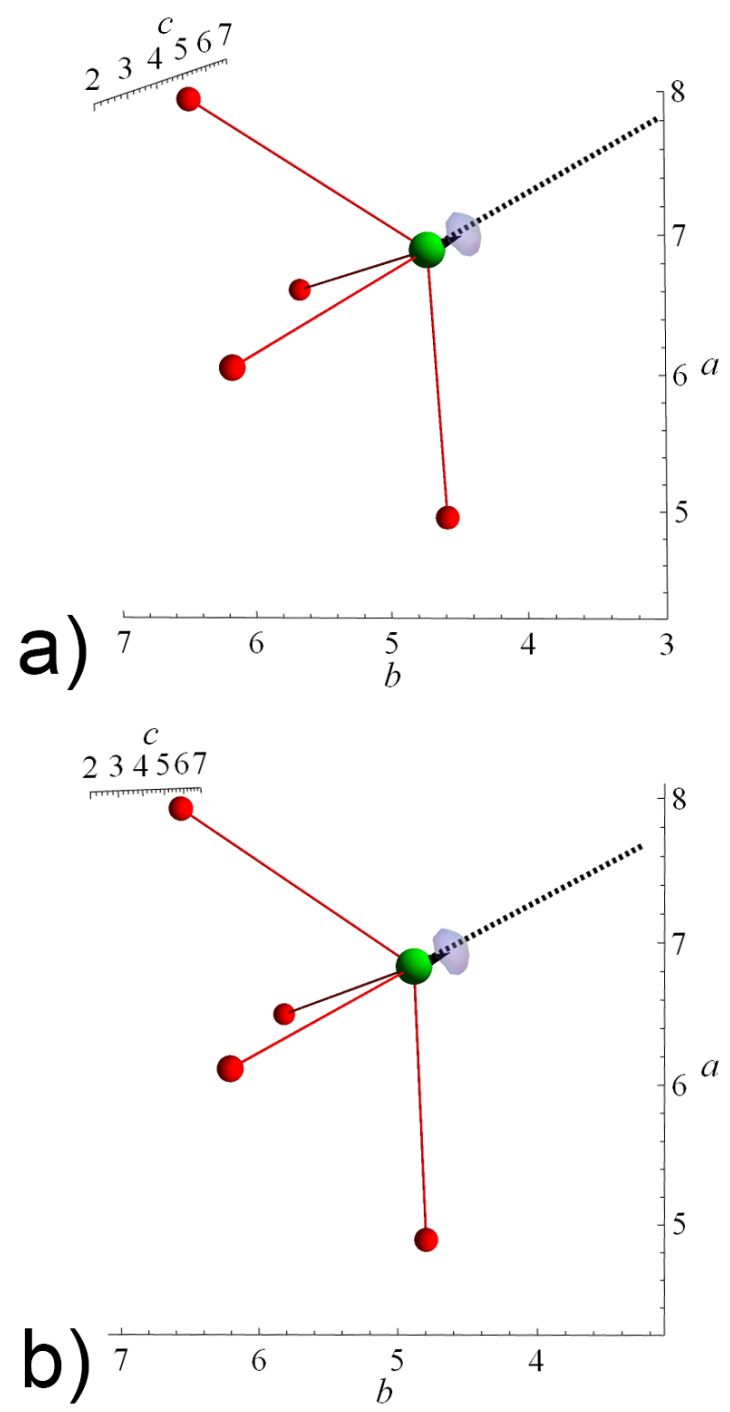

Figure 10. Charge-density difference isosurfaces and first coordination sphere of $\mathrm{Sn}$ in (a) $\mathrm{SnAlBO}_{4}$ and (b) $\mathrm{SnGaBO}_{4}$ using the isovalue $0.009 \mathrm{e} / 10^{6} \mathrm{pm}^{3}$. The dotted line represents the direction of the Wang-Liebau eccentricity vector, while the liebau density vectors are shown as black arrows.

the $x(a)$ and $y(b)$ polarization is almost negligible compared to the $z(c)$ direction, parallel to the octahedral $\mathrm{MO}_{6}$ chains. Additionally, the first maxima are located at much higher energies between 4 and $5 \mathrm{eV}$. Thus, we predict strong directional effects for UV-visible spectra on single-crystals. Regarding the absorption spectra of $\mathrm{SnGaBO}_{4}$, since its electronic structure is analogous to that of $\mathrm{SnAlBO}_{4}$ (figure 8), we expect that the general features are similar to those in figure 9, with the only significant difference being probably a blue shift inferred by the larger DFT electronic bandgap for the Ga compound $(4.44 \mathrm{eV})$.

As discussed in the previous sections, the structural properties of mullite-type $\mathrm{O} 8\left(\mathrm{LMBO}_{4}, \mathrm{ML}_{2} \mathrm{O}_{4}\right)$, O9 $\left(\mathrm{L}_{2} \mathrm{M}_{4} \mathrm{O}_{9}\right)$ and $\mathrm{O} 10\left(\mathrm{~L}_{2} \mathrm{M}_{4} \mathrm{O}_{10}\right)\{\mathrm{L}=$ lone electron pair carrying element, $\mathrm{M}=$ metal $\}$ compounds are often related to the stereochemical activities of the LEPs $[4,16,37,43-46]$. The calculated chargedensity difference isosurfaces of the $\mathrm{Sn}^{2+}$ LEP are displayed in figure 10. The isosurfaces occupy a small region, even when using lower isovalues than that of the scale $\left(0.009 \mathrm{e} / 10^{6} \mathrm{pm}^{3}\right)$. The liebau density vectors [17] show, in both cases, short lengths of about $32 \mathrm{pm}$. Regarding the Wang-Liebau vectors [20] we observe, in agreement with previous findings [17], that their direction practically crosses the points of maximum charge in the LEPs. The Wang-Liebau eccentricity (WLE) parameters $|\Phi|$ are $2.88 \times 10^{-5}$ and $2.58 \times 10^{-5}$ for $\mathrm{SnAlBO}_{4}$ and $\mathrm{SnGaBO}_{4}$, respectively, showing a similar stereochemical activity for both compounds, alike the Liebau Density Vector lengths. For comparison, the WLE parameters of $\mathrm{PbAlBO}_{4}$ and $\mathrm{PbGaBO}_{4}$ are $2.0 \times 10^{-5}$ and $1.9 \times 10^{-5}$, respectively [6]. The relatively large value of $|\Phi|$ for $\mathrm{SnMBO}_{4}$ indicates that the geometric disposition of $\mathrm{O}$-atoms in the first coordination sphere around $\mathrm{Sn}^{2+}$ is considerably asymmetric, however, its LEP occupies a rather small volume (figure 10).

In their revised model of the LEP, Walsh et al [47] argued that the stereochemical activity originates from the interaction of cation $s^{2}$-(e.g. $\left.\operatorname{Sn}(5 s)\right)$ with the anion $\mathrm{n} p$-states (e.g. $\mathrm{O}(2 p))$, giving rise to bonding $(\mathrm{Sn}(5 p)-\mathrm{O}(2 p))$ and antibonding $(\operatorname{Sn}(5 p)-\mathrm{O}(2 p) *)$ states in the lower and upper parts of the valence band, respectively. This, together with the lattice distortion, allows the unoccupied $\operatorname{Sn}(5 p)$ orbitals to hybridize with the $\operatorname{Sn}(5 s)-\mathrm{O}(2 p) *$ states, yielding an asymmetric electronic distribution. However, at which extent the interaction between the unoccupied $\operatorname{Sn}(5 p)$ and $\operatorname{Sn}(5 s)-\mathrm{O}(2 p) *$ will occur depends on the relative energy of both $\mathrm{Sn}(5 s)$ and $\mathrm{O}(2 p)$, leading to raise the $\mathrm{Sn}(5 s)-\mathrm{O}(2 p) *$ states at an optimized level. Moreover, since the $\operatorname{Sn}(5 p)$ states interact with the anti-bonding levels, it is crucial for the Sn-cation on-site hybridisation that the $\mathrm{Sn}(5 s)-\mathrm{O}(2 p) *$ states must have a substantial component of the $\operatorname{Sn}(5 s)$ states. That is, a larger $\operatorname{Sn}(5 s)$ character increases the stabilisation of the $\mathrm{Sn}(5 s)-\mathrm{O}(2 p) *$ states. The crystal orbital overlap population (COOP) for the $\mathrm{Sn}-\mathrm{O}$ and $\mathrm{Pb}-\mathrm{O}$ interactions, respectively calculated for $\mathrm{PbAlBO}_{4}$ and $\mathrm{SnAlBO}_{4}$, are shown in figure S2. Notably, the integrated COOP value can be used to quantify the bonding between the $\mathrm{M}$ and $\mathrm{O}$ orbital centres with positive and negative values corresponding to bonding and antibonding interactions [29]. The COOP comprises of about $10 \%$ and $21 \%$ integrated positive value for $\mathrm{PbAlBO}_{4}$ and $\mathrm{SnAlBO}_{4}$, respectively. The respective rest of the negative values in the upper part of the valence band refers to antibonding interactions. Beside the lattice distortion, the COOP analysis qualitatively shows that the $5 \mathrm{~s}^{2}$ and $6 \mathrm{~s}^{2}$ states bear stereochemically active LEP character, however, with different magnitude. The higher positive COOP value is consistent with the higher WLE of the $\mathrm{Sn}^{2+}$ LEPs than that of $\mathrm{Pb}^{2+}$ LEPs with a relative smaller positive COOP. Therefore, even if the electron distribution around the $\mathrm{Sn}^{2+}$ cation is more asymmetric, the likely reduced volume of the $5 \mathrm{~s}^{2}$ LEPs may not affect the bulk elastic properties as strongly as the larger $6 s^{2} \mathrm{LEP}$ in $\mathrm{PbMBO}_{4}$, which seems to be responsible for the associated anomalous properties.

\section{Conclusions}

First-principles calculations based on the hybrid PW1PW functional show that $\mathrm{SnAlBO}_{4}$ and $\mathrm{SnGaBO}_{4}$ could be synthesized 
from their corresponding oxides under low oxygen partial pressure and relatively high temperatures. A detailed structural characterization was performed on the proposed compounds, and a comparison has been made with structurally related $\mathrm{PbAlBO}_{4}$. The behaviour of the lone electron pairs in the Sn compounds contrasts with those of $\mathrm{Pb}$ : while the Wang-Liebau eccentricity parameters show relatively large values, the liebau density vectors are very short. This indicates an asymmetric first coordination shell of $\mathrm{Sn}^{2+}$ cations but a relatively small volume of the LEP. This impacts in the elastic properties: $\mathrm{SnMBO}_{4}$ show a larger bulk modulus and no axial negative linear compressibility below $20 \mathrm{GPa}$, in contrast to $\mathrm{PbMBO}_{4}$ where the strong stereochemical activity of $\mathrm{Pb}^{2+}$ contributes to their anomalous behaviour. The low quantity of negative mode-Grüneisen parameters supports this prediction, while it could also be an indication of the lack of axial negative thermal expansion. The calculation and assignment of the infrared and Raman spectra will serve as a reference for future experimental results. Moreover, we calculated the optical absorption spectrum of the title compounds using the $G W$-BSE method, and found a strong anisotropic character, with low-lying excited states polarized along the $c$-direction, parallel to the $1 \mathrm{D} \mathrm{MO}_{6}$ chains.

\section{Acknowledgments}

The authors acknowledge UNMDP (EXA 794/16 and EXA $898 / 18$ ) for the financial support. CBM is member of the research staff of Consejo Nacional de Investigaciones Científicas y Técnicas (CONICET). MC is grateful to CONICET for his postdoctoral fellowship, and to the Deutscher Akademischer Austauschdienst (DAAD) together with the Ministerio de Educación, Cultura, Ciencia y Tecnología (Argentina) for his ALEARG scholarship. The calculations presented here were mainly carried out on the cluster system at the Leibniz Universität Hannover, Germany. MMM gratefully thanks University of Bremen.

\section{ORCID iDs}

Mariano Curti (1) https://orcid.org/0000-0002-3721-4358

Cecilia B Mendive (i) https://orcid.org/0000-0002-9559-9268

M Mangir Murshed (1) https://orcid.org/0000-0002-9063-372X

Thorsten M Gesing (1) https://orcid.org/0000-0002-4119-2219

\section{References}

[1] Park $\mathrm{H}$ and Barbier $\mathrm{J} 2001 \mathrm{PbGaBO}_{4}$, an orthoborate with a new structure-type Acta Crystallogr. E 57 i82-4

[2] Park H, Lam R, Greedan J E and Barbier J 2003 Synthesis, crystal structure, crystal chemistry, and magnetic properties of $\mathrm{PbMBO}_{4}(\mathrm{M}=\mathrm{Cr}, \mathrm{Mn}, \mathrm{Fe})$ : a new structure type exhibiting one-dimensional magnetism Chem. Mater. 15 1703-12

[3] Park H, Barbier J and Hammond R P 2003 Crystal structure and polymorphism of $\mathrm{PbAlBO}_{4}$ Solid State Sci. 5 565-71
[4] Murshed M M, Mendive C B, Curti M, Nénert G, Kalita P E, Lipinska K, Cornelius A L, Huq A and Gesing T M 2014 Anisotropic lattice thermal expansion of $\mathrm{PbFeBO}_{4}$ : a study by x-ray and neutron diffraction, Raman spectroscopy and DFT calculations Mater. Res. Bull. 59 170-8

[5] Kalita P E 2014 High pressure behavior of mullite-type oxides: phase transitions, amorphization, negative linear compressibility and microstructural implications Doctoral Thesis University of Nevada, Las Vegas

[6] Murshed M M, Fischer R X and Gesing T M 2012 The role of the $\mathrm{Pb}^{2+}$ lone electron pair for bond valence sum analysis in mullite-type $\mathrm{PbMBO}_{4}(\mathrm{M}=\mathrm{Al}, \mathrm{Mn}$ and $\mathrm{Fe}$ ) compounds $Z$. Kristallogr. 227 580-4

[7] Koo H J and Whangbo M H 2009 Density functional investigation of the magnetic properties of $\mathrm{PbMBO}_{4}$ $(\mathrm{M}=\mathrm{Cr}, \mathrm{Mn}, \mathrm{Fe})$ Solid State Commun. $149602-4$

[8] Persson I, D'Angelo P and Lundberg D 2016 Hydrated and solvated Tin(II) ions in solution and the solid state, and a coordination chemistry overview of the $\mathrm{d}^{10} \mathrm{~s}^{2}$ metal ions Chem. Eur. J. 22 18583-92

[9] Drago R S 1958 Thermodynamic evaluation of the inert pair effect J. Phys. Chem. 62 353-7

[10] Donaldson J D 2007 The chemistry of bivalent tin Progress in Inorganic Chemistry (New York: Wiley-Blackwell) pp 287-356

[11] Bredow T and Gerson A 2000 Effect of exchange and correlation on bulk properties of $\mathrm{MgO}, \mathrm{NiO}$, and $\mathrm{CoO}$ Phys. Rev. B 61 5194-201

[12] Nakhal S, Lumey M W, Bredow T, Dronskowski R and Lerch M 2010 Synthesis and approximated crystal and electronic structure of a proposed new tantalum oxide nitride $\mathrm{Ta}_{3} \mathrm{O}_{6} \mathrm{~N}$ Z. Anorg. Allg. Chem. 636 1006-12

[13] Homann T, Hotje U, Binnewies M, Börger A, Becker K D and Bredow T 2006 Composition-dependent band gap in $\mathrm{ZnS}_{x} \mathrm{Se}_{1-x}$ : a combined experimental and theoretical study Solid State Sci. 8 44-9

[14] Islam M M, Maslyuk V, Bredow T and Minot C 2005 Structural and electronic properties of $\mathrm{Li}_{2} \mathrm{~B}_{4} \mathrm{O}_{7} J$. Phys. Chem. B 109 13597-604

[15] Gesing T M, Mendive C B, Curti M, Hansmann D, Nénert G, Kalita P E, Lipinska K E, Huq A, Cornelius A L and Murshed M M 2013 Structural properties of mullite-type $\mathrm{Pb}\left(\mathrm{Al}_{1-x} \mathrm{Mn}_{x}\right) \mathrm{BO}_{4}$ Z. Kristallogr. Cryst. Mater. 228 532-43

[16] Murshed M M, Mendive C B, Curti M, Šehovic M, Friedrich A, Fischer M and Gesing T M 2015 Thermal expansion of mullite-type $\mathrm{Bi}_{2} \mathrm{Al}_{4} \mathrm{O}_{9}$ : a study by $\mathrm{x}$-ray diffraction, vibrational spectroscopy and density functional theory J. Solid State Chem. 229 87-96

[17] Curti M, Gesing T M, Murshed M M, Bredow T and Mendive C B 2013 Liebau density vector: a new approach to characterize lone electron pairs in mullite-type materials Z. Kristallogr. Cryst. Mater. 228 629-34

[18] Paier J, Marsman M and Kresse G 2008 Dielectric properties and excitons for extended systems from hybrid functionals Phys. Rev. B 78121201

[19] Onida G, Reining L and Rubio A 2002 Electronic excitations: density-functional versus many-body Green's-function approaches Rev. Mod. Phys. 74 601-59

[20] Wang X and Liebau F 1996 Influence of lone-pair electrons of cations on bond-valence parameters Z. Kristallogr. Cryst. Mater. 211 437-9

[21] Dovesi R, Orlando R, Civalleri B, Roetti C, Saunders V R and Zicovich-Wilson C M 2005 CRYSTAL: a computational tool for the ab initio study of the electronic properties of crystals Z. Kristallogr. 220 571-3

[22] Perdew J, Chevary J, Vosko S, Jackson K, Pederson M, Singh D and Fiolhais C 1992 Atoms, molecules, solids, and surfaces: applications of the generalized gradient 
approximation for exchange and correlation Phys. Rev. B 46 6671-87

[23] Anderson D G 1965 Iterative procedures for nonlinear integral equations J. ACM 12 547-60

[24] Pascale F, Zicovich-Wilson C M, López Gejo F, Civalleri B, Orlando R and Dovesi R 2004 The calculation of the vibrational frequencies of crystalline compounds and its implementation in the CRYSTAL code J. Comput. Chem. 25 888-97

[25] Zicovich-Wilson C M, Pascale F, Roetti C, Saunders V R, Orlando R and Dovesi R 2004 Calculation of the vibration frequencies of $\alpha$-quartz: the effect of Hamiltonian and basis set J. Comput. Chem. 25 1873-81

[26] Ferrero M, Rrat M, Orlando R and Dovesi R 2008 Coupled perturbed Hartree-Fock for periodic systems: the role of symmetry and related computational aspects J. Chem. Phys. 128014110

[27] Ferrero M, Rérat M, Orlando R and Dovesi R 2008 The calculation of static polarizabilities of $1-3 \mathrm{D}$ periodic compounds. The implementation in the crystal code J. Comput. Chem. 29 1450-9

[28] Ferrero M, Kirtman B and Dovesi R 2008 Calculation of first and second static hyperpolarizabilities of one- to threedimensional periodic compounds. Implementation in the Crystal code J. Chem. Phys. 129244110

[29] Ruggiero M T, Erba A, Orlando R and Korter T M 2015 Origins of contrasting copper coordination geometries in crystalline copper sulfate pentahydrate Phys. Chem. Chem. Phys. 17 31023-9

[30] Dovesi R et al 2018 Quantum-mechanical condensed matter simulations with CRYSTAL, Wiley Interdiscip Rev. Comput. Mol. Sci. 8 e 1360

[31] Enkovaara J et al 2010 Electronic structure calculations with GPAW: a real-space implementation of the projector augmented-wave method J. Phys.: Condens. Matter 22253202

[32] Schmidt P S, Patrick C E and Thygesen K S 2017 Simple vertex correction improves GW band energies of bulk and two-dimensional crystals Phys. Rev. B 96205206

[33] Dirac P A M 1930 Note on exchange phenomena in the thomas atom Math. Proc. Cambridge Phil. Soc. 26376

[34] Reimann C, Weber D, Lerch M and Bredow T 2013 Nonstoichiometry in bixbyite-type vanadium sesquioxide J. Phys. Chem. C 117 20164-70
[35] Sun W, Dacek S T, Ong S P, Hautier G, Jain A, Richards W D, Gamst A C, Persson K A and Ceder G 2016 The thermodynamic scale of inorganic crystalline metastability Sci. Adv. 2 e 1600225

[36] Shannon R D 1976 Revised effective ionic radii and systematic studies of interatomic distances in halides and chalcogenides Acta Crystallogr. A 32 751-67

[37] Kirsch A, Murshed M M, Litterst F J and Gesing T M 2019 Structural, spectroscopic, and thermoanalytic studies on $\mathrm{Bi}_{2} \mathrm{Fe}_{4} \mathrm{O}_{9}$ : tunable properties driven by nano- and polycrystalline states J. Phys. Chem. C 123 3161-71

[38] Anderson O L and Nafe J E 1965 The bulk modulus-volume relationship for oxide compounds and related geophysical problems J. Geophys. Res. 703951

[39] Friedrich A, Biehler J, Morgenroth W, Wiehl L, Winkler B, Hanfland M, Tolkiehn M, Burianek M and Mühlberg M 2012 High-pressure phase transition of $\mathrm{Bi}_{2} \mathrm{Fe}_{4} \mathrm{O}_{9} J$. Phys.: Condens. Matter 24145401

[40] Cairns A B and Goodwin A L 2015 Negative linear compressibility Phys. Chem. Chem. Phys. 17 20449-65

[41] Haussühl S, Bohatý L and Becker P 2006 Piezoelectric and elastic properties of the nonlinear optical material bismuth triborate, $\mathrm{BiB}_{3} \mathrm{O}_{6}$ Appl. Phys. A 82 495-502

[42] Barrera G D, Bruno J A O, Barron T H K and Allan N L 2005 Negative thermal expansion J. Phys.: Condens. Matter. 17 R217-52

[43] Schneider H, Fischer R X, Gesing T M, Schreuer J and Muhlberg M 2012 Crystal chemistry and properties of mullitetype $\mathrm{Bi}_{2} \mathrm{M}_{4} \mathrm{O}_{9}$ : an overview Int. J. Mater. Res. $103422-9$

[44] Ziegler F, Murshed M M, Gibhardt H, Sobolev O, Gesing T M and Eckold G 2016 Mechanical properties of multiferroic $\mathrm{Bi}_{2} \mathrm{Mn}_{4} \mathrm{O}_{10}$ : full set of elastic constants determined by inelastic neutron scattering Phys. Status Solidi 253 976-82

[45] Murshed M M, Rusen A, Fischer R X and Gesing T M 2012 Transition-metal substitution in $\mathrm{PbAlBO}_{4}$ : synthesis, structural and spectroscopic studies of manganese containing phases Mater. Res. Bull. 47 1323-30

[46] Murshed M M and Gesing T M 2013 Anisotropic thermal expansion and anharmonic phonon behavior of mullite-type $\mathrm{Bi}_{2} \mathrm{Ga}_{4} \mathrm{O}_{9}$ Mater. Res. Bull. 48 3284-91

[47] Walsh A, Payne D J, Egdell R G and Watson G W 2011 Stereochemistry of post-transition metal oxides: revision of the classical lone pair model Chem. Soc. Rev. $\mathbf{4 0} 4455$ 